\title{
Strength Assessment of Structural Elements
}

\section{K. Baskaran and S. Sivanerupan}

\begin{abstract}
Reinforced concrete structures, built in the last century, are reaching end of their life span and need strength assessment for their continuous safe use. Strength assessment is also required with increase in loads due to change in use or increasing weight of applied loading. Quite often people use finite element programs based on linear elastic theory to assess the carrying capacity of structural elements. However, the real behaviour of reinforced concrete structures in the vicinity of failure is plastic. In this paper, assessment methods based on nonlinear finite element (NLFE) method (using DIANA) and yield line theory (followin $r$ the hodograph approach) are explained. In addition, new yield line mechanisms for flat slabs supported on non-rectangular column grid are introduced and compared with experimental observations and NLFE predictions. Based on comparison between the predictions by NLFE and Yield line theory conclusions are made.
\end{abstract}

Keywords: Strength, Yield line, Nonlinear, Plasticity

\section{Introduction}

Reinforced concrete structures, such as buildings, bridges and transmission poles etc, built in the last century, are reaching end of their life span and need strength assessment for their continuous safe use. The loads applied on structures are also changing with the dynamic changes in technology and life style, change in use etc. One approach to these problems may be to replace the existing structure with a new one. However, this is an expensive approach. Instead, one can assess the load carrying capacity and if there is any deficit in carrying capacity then can strengthen the structure. To avoid unnecessary interference, in the form of strengthening with the use of the structure, it is very important to assess the carrying capacity as accurate as possible.

Linear elastic theory is well established and understood. It is supported by many computer software packages, and has been found most satisfactory for the design of structural elements. As a lower-bound method the engineer can be confident that the analysis method is conservative and hence leads to safe estimates. In linear analysis we assume that displacements and rotations are small, supports do not settle, stress is directly proportional to strain, and loads maintain their original directions as the structure deforms.

Linear elastic finite element analysis is considered to give very approximate solutions for the analysis of reinforced concrete elements because on cracking, the section moduli are no longer uniform. This is because tensile forces are released by cracked concrete to the reinforcement and moments are redistributed due to the local yielding of reinforcement. Most of the convenient assumptions that lead to a linear analysis may be at odds with reality.

In some structures with loading part of the structure may loose stiffness because of buckling or failure of the material. Displacements and rotations may become large enough that equilibrium equations must be written at deformed configuration rather than the original configuration. Large rotations cause pressure loads to change in direction and also in magnitude if there is a change in the area to which they are applied.

Since the real behaviour of reinforced concrete elements at failure is plastic, the assessment methods should be based on plasticity theories. The tools, which can be used to evaluate the flexural capacity of structural elements in the ultimate limit state, are yield line analysis and non linear finite element analysis.

Non Linear Finite Element Analysis is capable of taking in to account of concrete cracking and crushing, reinforcement yielding, membrane action, large displacement etc. NLFEA can be considered as a tool with a capability of

Dr. K. Baskaran., B.Sc. Eng. (Hons)(Peradeniya),PhD (Cambridge) Senior Lecturer, Department of Civil Engineering, University of Moratuwa.

Eng. S Sivanerupan., B.Sc. Eng. (Hons) (Moratuwa), AMIE(SL) 
predicting real failure loads for concrete structures than conventional methods. Up to now the NLFE method is more suited to indepth, specialised assessments of major structures or for laboratory research, and is not presently considered to be a practical option for use in assessing structural elements in Sri Lanka. This situation could well change in the future as developments in computer industry continuously result in decreasing costs and greater speed with NLFE programs. However, the sensitivity of results, need for calibration, and specialised expertise required are still likely to limit their application.

Nonlinearity makes a problem more complicated because the solutions can not be obtained in a single step analysis. We must take several steps, update the tentative solutions after each step, and repeat until a convergence test is satisfied. The usual linear analysis is only the first step in this sequence.

Yield-line analysis is an upper bound method for the prediction of ultimate flexural strength of slabs and some other structural elements. Unlike NLFEA, the yield line analysis is a proven tool by comparing with lots of structural experimental data [1-5]. Major difficulty involved with yield line analysis is the determination of the worst mechanism. However the use of yield line theory has been decreasing due to non availability of computer programs based on yield line theory. The purpose of this paper is to encourage the use of yield line theory in strength assessment of slabs.

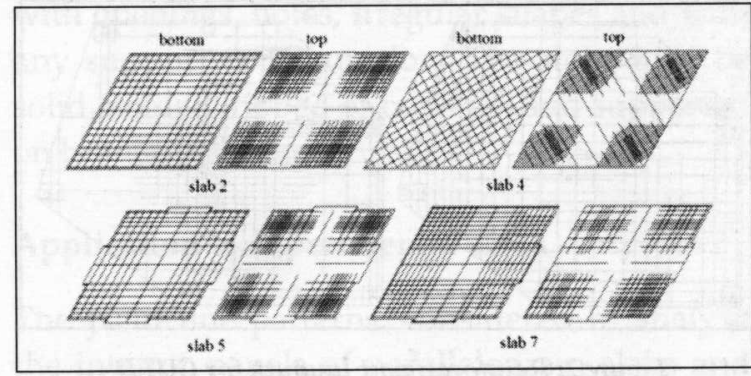

$\begin{array}{ll}\text { (a). Bottom reinforcement } & \text { (b) Top reinforcement }\end{array}$

Figure 1: Reinforcement layouts for parallelogram slab specimens

Some experimental details of flat slab specimens [6], tested at Cambridge University Engineering Department (CUED), relevant to this paper are described in section two. In the following section yield line analysis based on hodograph approach is briefly explained. This is followed by details of nonlinear finite element model adopted for the modelling of experimental slabs. Yield line and nonlinear finite element predictions are compared with experimental results before concluding the paper.

\section{Experimental study}

Experimental slabs 2, 4, 5 and 7 were flat slab panels supported on four columns in a 30 degree skew layout with $1200 \mathrm{~mm}$ column centre to centre spacing. The reinforcement layouts of these specimens are shown in Figure 1 and some details of the specimen are tabulated in Table 1. Slab 9 was $50 \mathrm{~mm}$ in thickness and supported by seven columns in a completely irregular grid. Reinforcement layout of seven-column

Table 1: Details of experimental slabs

\begin{tabular}{|c|c|c|c|c|c|c|c|}
\hline $\begin{array}{l}\text { हूँ } \\
\text { के } \\
\text { के }\end{array}$ & 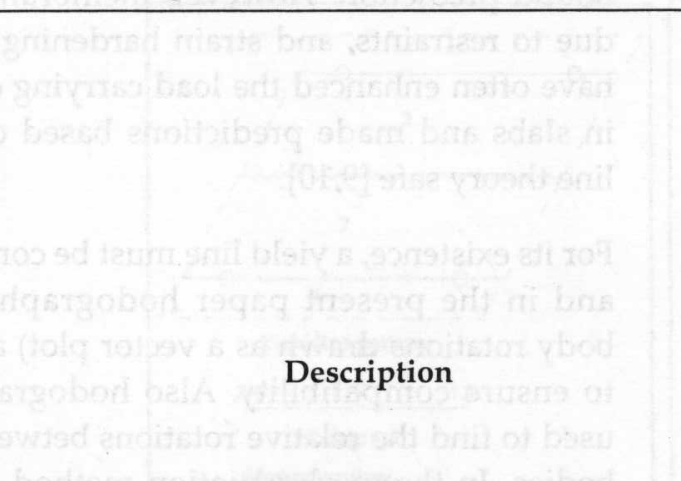 & 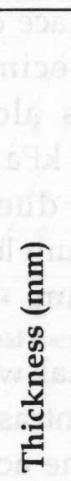 & 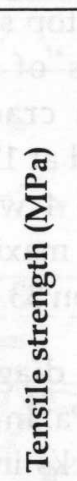 & 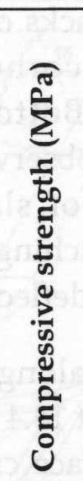 & 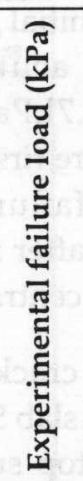 & 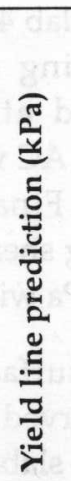 & 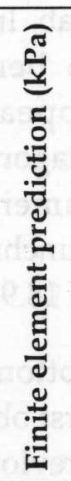 \\
\hline Slab 2 & Interior panel of a parallelogram column layout & 50 & 3.19 & 46.3 & 20.0 & 21.3 & 20.7 \\
\hline Slab 4 & Interior panel of a parallelogram column layout & 50 & 3.22 & 51.3 & 18.9 & 19.4 & 19.5 \\
\hline Slab 5 & Interior panel of a parallelogram column layout & 60 & 3.18 & 51.5 & 25.3 & 24.8 & 23.0 \\
\hline Slab 7 & Corner panel of a parallelogram column layout & 60 & 3.4 & 48.1 & 23.8 & 26.3 & 24.0 \\
\hline Slab 9 & Irregular & 50 & 3.47 & 45.2 & 25.9 & 25.3 & 30.1 \\
\hline
\end{tabular}




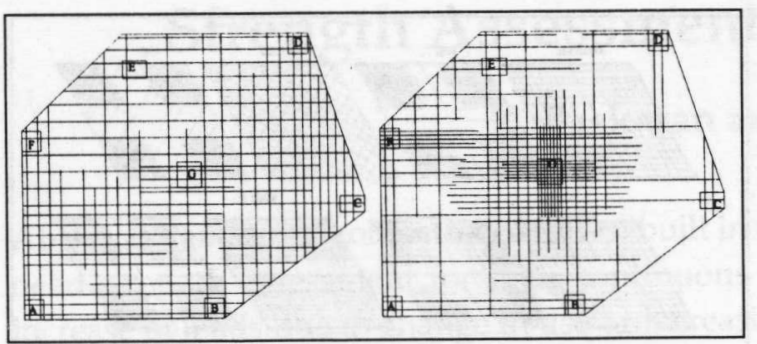

Figure 2: Reinforcement layouts for CUED seven-column specimen (slab 9)

specimen is shown in Figure 2. Mild steel bars, $4 \mathrm{~mm}$ in diameter and having yield strength 395 $\mathrm{MPa}$, were used in all the specimens. From a mix design, ingredients for concrete was selected in the following ratios

From control specimens, in the form of cubes and cylinders, compressive strength and tensile strength were obtained and averaged values are given in Table 1.

The specimens were tested in a vacuum rig under uniformly distributed load (for details of the vacuum rig refer elsewhere [7]). For interior panels and corner panels, contra-flexure lines were selected as boundaries along continuous edges and edge shear forces calculated according to strip theories were applied using steel plates. During the test in addition to the load, strain and deflection measurements at various locations, were monitored using a data logger.

In slab 2, cracks on top surface appeared at $9.2 \mathrm{kPa}$ and those on bottom surface formed at $12.8 \mathrm{kPa}$. Loading was discontinued in slab 2 at $20.0 \mathrm{kPa}$ with central deflection measuring $45 \mathrm{~mm}$ to avoid breaking the camera below the slab. In slab 4, initial cracks on top surface due to bending of acute corners of specimen appeared at $9.7 \mathrm{kPa}$. Bottom cracks along diagonal $\mathrm{AC}$ were first observed at $12.3 \mathrm{kPa}$ via camera. Final failure of slab 4 was due to punching shear after reaching a maximum load of $18.9 \mathrm{kPa}$ with central deflection $33.6 \mathrm{~mm}$.

Bottom surface cracks along a diagonal were first observed in slab 5 at $13.4 \mathrm{kPa}$. In contrast to previous slabs, top surface cracks in the acute corners formed at a higher load $(20.3 \mathrm{kPa})$. Final failure of slab 5 was due to fracture of rebar, after yielding at $25.3 \mathrm{kPa}$ with central deflection $43 \mathrm{~mm}$. In the corner panel, top surface cracks appeared above column $\mathrm{B}$ at $18.9 \mathrm{kPa}$. Alsu final failure occurred at $23.8 \mathrm{kPa}$ due to punching of the same column.

In the CUED seven column specimen (see Figure 2 for locations) cracks were first observed above column $\mathrm{G}$ on the top surface around 14.8 $\mathrm{kPa}$. With further loading hogging cracks were appeared above column $\mathrm{F}$ and along column line $B G$ at $16.5 \mathrm{kPa}$. Top surface cracks along column lines EG and FG formed between 18 and $19 \mathrm{kPa}$ loading. After reaching a peak load of $25.9 \mathrm{kPa}$ rotation about column $\mathrm{C}$ increased rapidly and reinforcement bars in panel BCDG yielded and snapped around that peak load.

\section{Assessment based on yield line analysis}

Ingerslev [8] proposed the yield line analysis in 1923 to assess the strength of slabs and Johansen [3] extended the application of yield line analysis by tests. Later, several researchers considered yield line analysis to assess the strength of slabs having rectangular layout and confirmed the validity of the theory.

In a yield line analysis, the ultimate load is calculated by postulating a failure mechanism, involving rigid slab portions rotating about axes of rotations, with plastically deforming boundaries (yield lines), satisfying compatibility with boundary conditions. This is based on the assumptions that final failure is due to flexure and enough ductility is available in the structure. As the structure has turned into a mechanism, the predicted collapse load is an upper bound value and unsafe. Therefore in theory it is required to find the lowest upper bound prediction. However, membrane action due to restraints, and strain hardening of steel have often enhanced the load carrying capacity in slabs and made predictions based on yield line theory safe $[9,10]$.

For its existence, a yield line must be compatible and in the present paper hodographs (rigid body rotations drawn as a vector plot) are used to ensure compatibility. Also hodographs are used to find the relative rotations between rigid bodies. In the work equation method of yield line analysis, the work done by the external forces is equated to the internal energy dissipated along the yield lines. The internal energy dissipated along the yield lines is: $\Sigma$ 
Moment/ unit width $x$ length of the yield line $x$ relative rotation between the rigid bodies across yield lines.

The work done by the external forces is $\Sigma$ (load $x$ distance moved by the point of application of the load in the direction of the load). For uniformly distributed load this can be easily calculated by dividing the rigid bodies into triangles and multiplying the areas of the triangles by their centroidal deflections. In the current paper also this method is followed to find the external work done. To find the areas, a CAD program was used. Rest of the calculations were done on an Excel spreadsheet.

Once understood, Yield Line analysis is quick and easy to apply. It may be used on all types of slabs and loading configurations that would otherwise be very difficult to analyse without sophisticated computer programs. It can deal with openings, holes, irregular shapes and with any support configuration. The slabs may be solid, voided, ribbed or coffered, and supported on beams, columns or walls.

\section{Application to experimental slabs}

The yield line patterns, considered to analyse the interior panels of parallelogram slabs and the corresponding hodographs, are shown in Figure 3. Two calculations, one considering the interior panel alone as a typical interior panel of a continuous slab and the other with the overhangs with edge shear to represent the boundary conditions as in the experiment were performed for each slab [11]. For each mechanism predicted failure loads are tabulated in Table 2 (see appendix for a sample calculation). Similar yield line patterns, with slight changes to accommodate the two free edges, were used to assess the corner column.
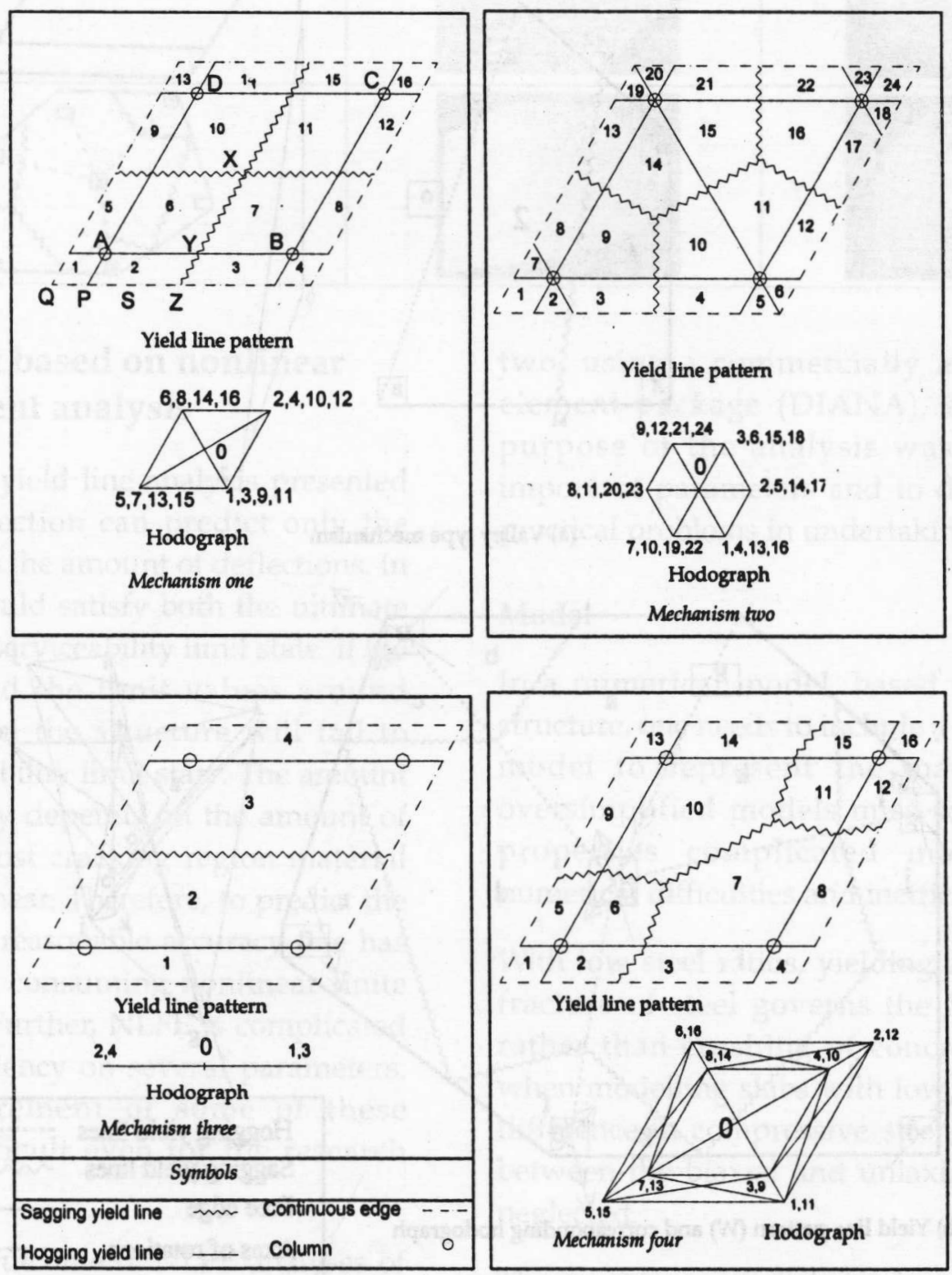

Figure 3: Yield line patterns considered for interior panel of parallelogram column layout 
Table 2: Predicted failure load from different yield line mechanisms

\begin{tabular}{|c|c|c|c|c|c|c|}
\hline \multirow{2}{*}{ Specimen } & \multicolumn{7}{|c|}{ Yield line mechanism } \\
\cline { 2 - 7 } & $\begin{array}{c}\text { Mechanism } \\
\text { one }\end{array}$ & $\begin{array}{c}\text { Mechanism } \\
\text { two }\end{array}$ & $\begin{array}{c}\text { Mechanism } \\
\text { three }\end{array}$ & $\begin{array}{c}\text { Mechanism } \\
\text { four }\end{array}$ & $\begin{array}{c}\text { Mechanism } \\
\text { P I }\end{array}$ & $\begin{array}{c}\text { Mechanism } \\
\text { W }\end{array}$ \\
\hline Slab 2 & 21.25 & 21.30 & 21.34 & 21.91 & - & - \\
Slab 4 & 19.98 & 21.07 & 20.65 & 19.41 & - & - \\
Slab 5 & 25.04 & 26.36 & 24.84 & 25.58 & - & - \\
Slab 7 & 26.84 & 27.24 & 26.34 & 26.62 & - & - \\
Slab 9 & - & - & - & - & 26.4 & 25.34 \\
\hline
\end{tabular}

In the seven column specimen, panel ABGEF was analysed for valley type failure mechanism prior to the test (see Figure 4a). This mechanism suggested a failure load of $26.4 \mathrm{kPa}$. However, the crack pattern and deflections in the experiment suggested a different failure mechanism (shown in Table 3). Based on this, a more complicated failure mechanism (mechanism W), shown in Figure $4 \mathrm{~b}$, was considered in which rigid slab bodies a, b, c, d, e, $f, g, h, i, j, k$, and 1 rotate about axes of rotations along column line GE, column D, column D, column $G$, column $C$, column B, column B, column A, column G, column F, column line EG and column $F$ respectively. This mechanism predicted the collapse load as $25.3 \mathrm{kPa}$.

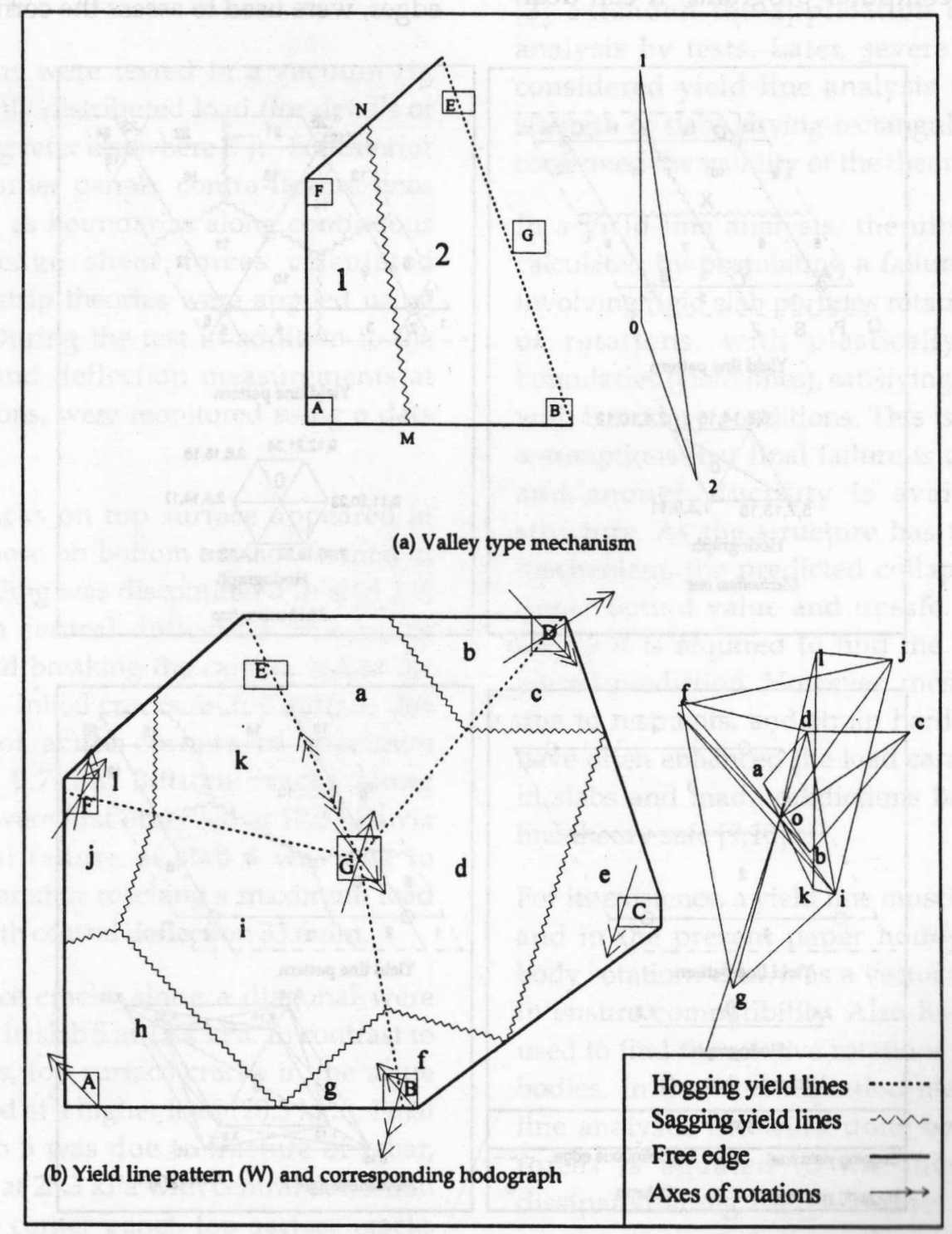

Figure 4: Yield line pattems considered to analyse CUED seven-column specimen 
Table 3: Comparison between experimental and yield line pattern suggested crack patterns

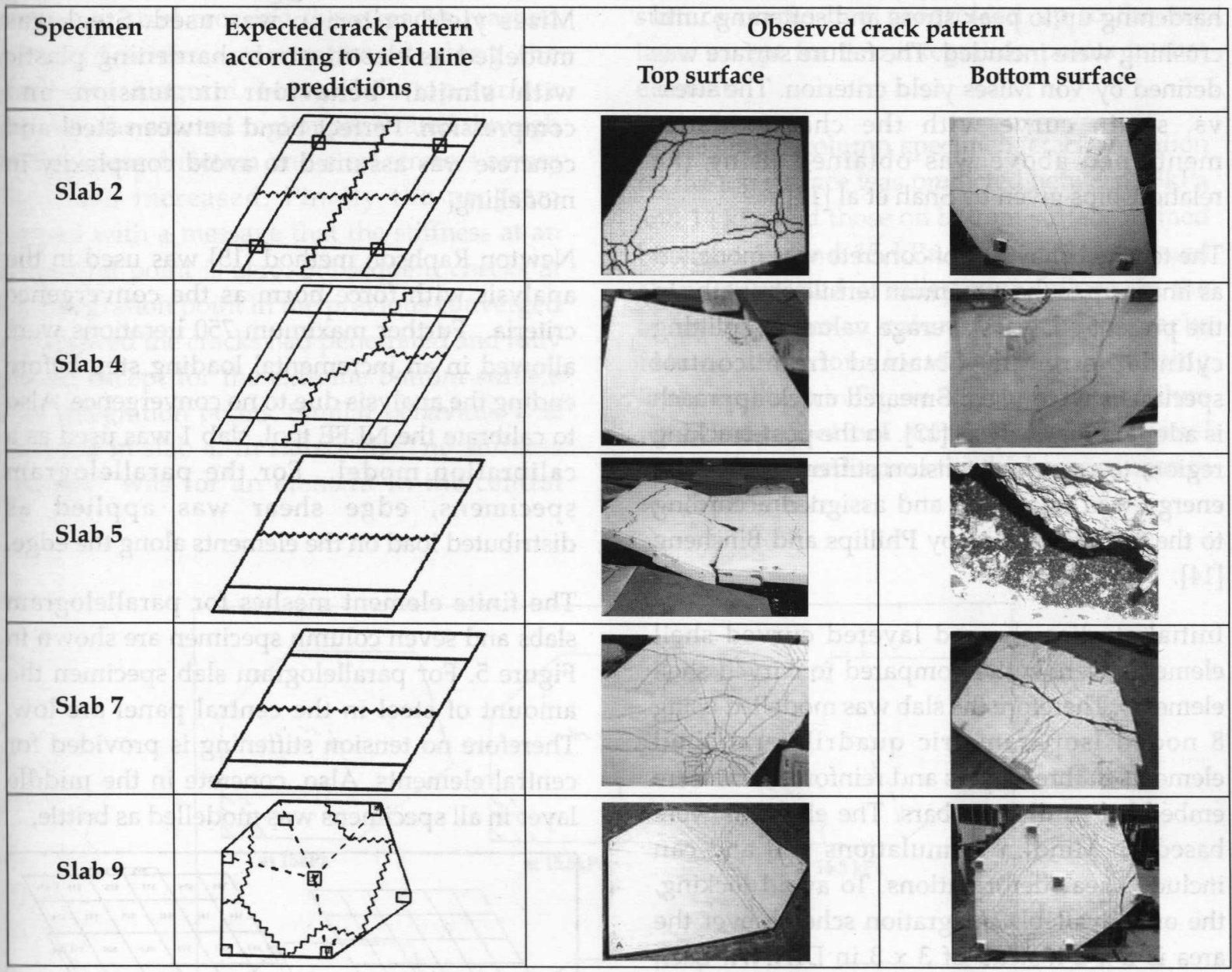

\section{Assessment based on nonlinear finite element analysis}

The upper bound yield line analysis presented in the previous section can predict only the failure load but not the amount of deflections. In practice a slab should satisfy both the ultimate limit state and the serviceability limit state. If the deflections exceed the limit values around working load then the structure will fail to satisfy the serviceability limit state. The amount of deflection highly depends on the amount of cracking. In the post cracking region material behaviour is nonlinear. Therefore, to predict the deflections within reasonable accuracy one has to perform a time consuming nonlinear finite element analysis. Further, NLFE is complicated due to the dependency on several parameters. Accurate measurement of some of these parameters is difficult even for the research community.

In this paper the outcome of NLFE analyses of the experimental slabs mentioned in section two, using a commercially available finite element package (DIANA), are given. The purpose of the analysis was to reveal the important parameters and to demonstrate the practical problems in undertaking such a task.

\section{Model}

In a numerical model, based on the type of structure, one needs to include a proper material model to represent the materials. While oversimplified models miss some important properties complicated models lead to numerical difficulties and inefficient analysis.

With low steel ratios, yielding and consequent fracture of steel governs the failure in slabs rather than crushing of concrete. Therefore, when modelling slabs with low steel ratios, the difference in compressive strength of concrete between the biaxial and uniaxial states can be neglected.

The input for concrete behaviour in compression was linear up to $40 \%$ of the peak strength, with 
secant modulus as the slope. Beyond that plastic hardening up to peak stress and softening until crushing were included. The failure surface was defined by Von Mises yield criterion. The stress vs. strain curve with the characteristics mentioned above was obtained using the relationships given by Shah et al [12].

The tensile behaviour of concrete was modelled as linear up to the maximum tensile strength. In the present analyses average values of splitting cylinder strength obtained from control specimens were used. Smeared crack approach is adopted for analysis [13]. In the post-cracking region, to represent tension stiffening, fracture energy was calculated and assigned according to the formulas given by Phillips and Binsheng [14].

Initial studies showed layered curved shell elements were better compared to curved shell elements. Therefore the slab was modelled using 8 noded isoparametric quadrilateral shell elements in three layers and reinforcement were embedded as discrete bars. The elements were based on Mindlin formulations [15] and can include shear deformations. To avoid locking, the only available integration scheme over the area is $2 \times 2$ instead of $3 \times 3$ in DIANA. Each node has three translational and two rotational degrees of freedom. Columns are modelled as point supports with no vertical translation.

The initiation of the first crack at an integration point is based on the principal stress exceeding the tensile strength of concrete. If multiple cracks are allowed to form with strength criterion alone then with small rotations in principal tensile stress, new cracks will form and close the existing cracks. To avoid this, the program allowed successive cracks to form only when the tensile stress exceeded the tensile strength and the angle between the two cracks is above a threshold angle (default value 60 degrees). The default value was used in the present modelling.

In the post-cracking region, contributions to shear resistance by various sources like aggregate interlock, dowel action etc were represented by a constant shear retention factor.

From a parametric study on various tension stiffening models, a linear tension softening model was selected for the present analysis. In compression a loading surface based on Von Mises yield criterion was used. Steel was modelled as elastic, strain hardening plastic with similar behaviour in tension and compression. Perfect bond between steel and concrete was assumed to avoid complexity in modelling.

Newton Raphson method [15] was used in the analysis with force norm as the convergence criteria. Further maximum 750 iterations were allowed in an incremental loading step before ending the analysis due to no convergence. Also to calibrate the NLFE tool, slab 1 was used as a calibration model. For the parallelogram specimens, edge shear was applied as distributed load on the elements along the edge.

The finite element meshes for parallelogram slabs and seven column specimen are shown in Figure 5. For parallelogram slab specimen the amount of steel in the central panel are low. Therefore no tension stiffening is provided for central elements. Also, concrete in the middle layer in all specimens was modelled as brittle.

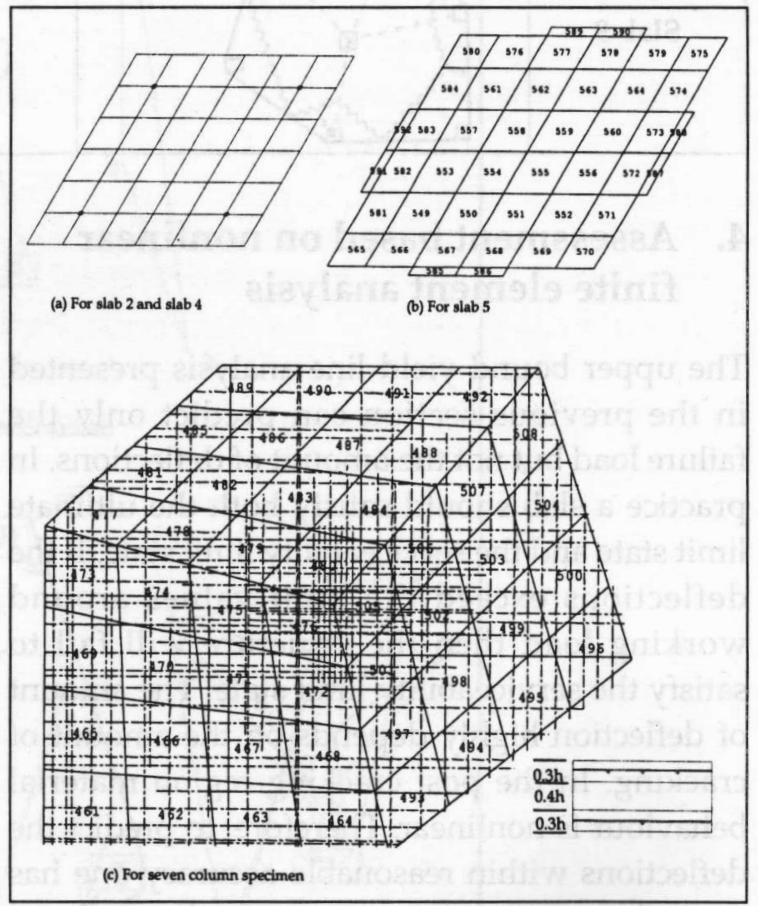

Figure 5: Finite element mesh used to analyse experimental slabs

\section{Finite element predictions}

In slab 2, the first cracks appeared on top surface above acute corner columns between $10 \mathrm{kPa}$ and $11 \mathrm{kPa}$. With increased loading the bottom surface cracks formed around $15 \mathrm{kPa}$ in slab 2 . With further progress in the analysis the bottom 
surface cracks extended along the middle strips. Stresses in steel crossing these cracks reached the yield stress and continued along the hardening diagram. Meanwhile top surface cracks in the column region penetrated through the thickness direction and steel stresses across them also increased. Finally the program stopped with a message that the stiffness at an integration point is zero. Subsequent checks at that integration point in the previous converged step showed the cracks had penetrated and fully opened except for the extreme bottom surface layer integration points. Similar behaviour was observed in slab 4 . In slab 5 , the "no stiffness message" was for an element in the central panel. In the previous converged step, bottom surface cracks had progressed up to the top layer except for two integration points in that element.

In the corner column specimen, crack initiation on the top surface was predicted between $13 \mathrm{kPa}$ and $14 \mathrm{kPa}$ and those on bottom surface formed between 14 and $15 \mathrm{kPa}$. The final deformed shape suggested a valley type failure. In the analysis of seven column specimen cracks formed at various locations with increasing loads as shown in Figure 6 . The predicted failure was due to bottom surface cracks in panel BCDG penetrated across the thickness as seen in the experiment.

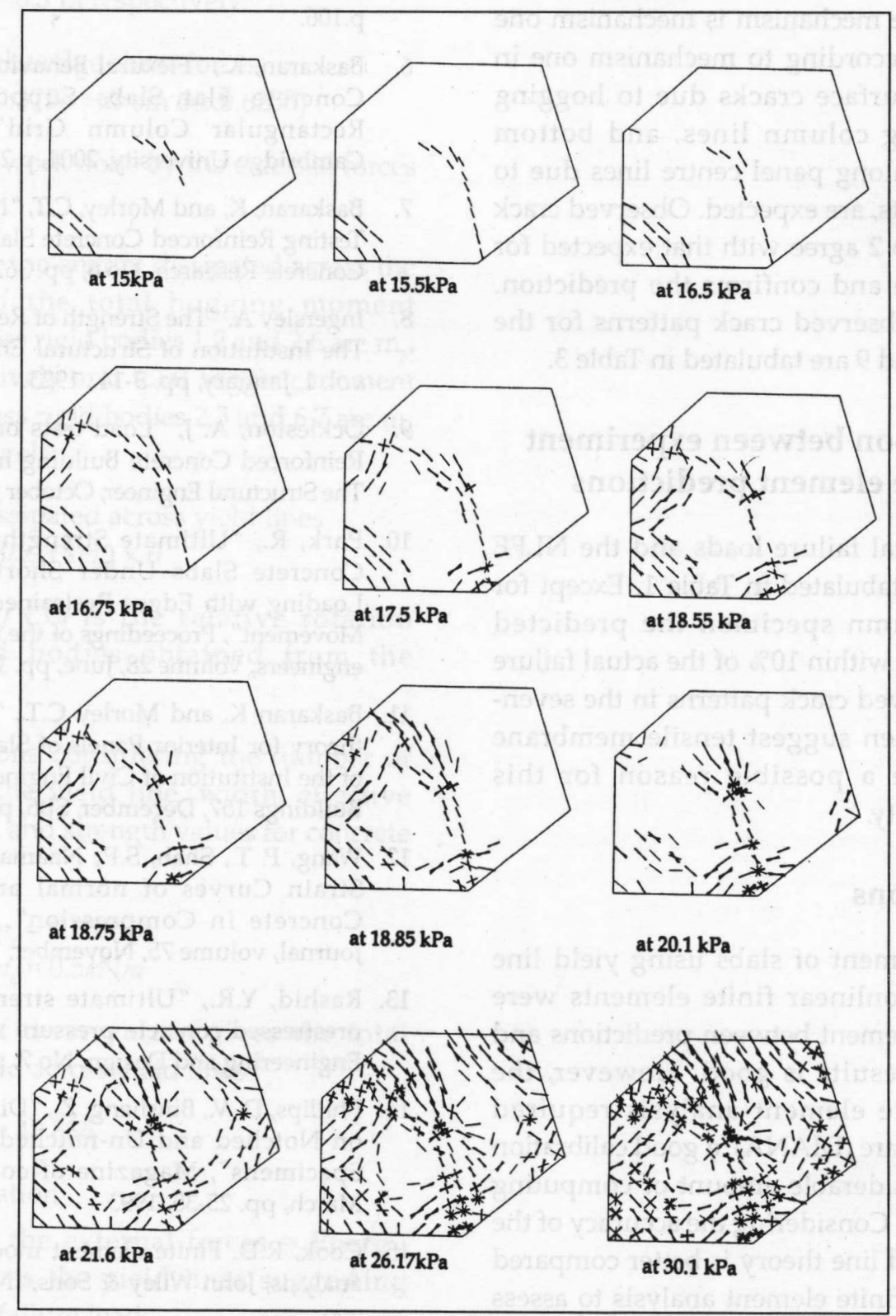

Figure 6: Predicted crack pattern for slab 9 at various stages in the NLFE analysis 


\section{Comparison between experiment and yield line predictions}

The predicted failure loads based on yield line analysis agrees well with the experimental failure loads (see Table 1). The maximum variation is about $10 \%$ for the corner panel. Punching shear intervening in the experiment prior to reaching full flexural capacity may be one reason for this variation. Also it may be due to less effort taken to optimise the location of yield lines to improve the prediction.

Top and bottom surface cracks are good indicators of yield line locations. Because yield lines are highly stressed regions in tension and concrete is weak in tension. For slab 2, considering the four yield line mechanisms the predicted failure mechanism is mechanism one (see Table 2). According to mechanism one in Figure 3, top surface cracks due to hogging moments along column lines, and bottom surface cracks along panel centre lines due to sagging moments, are expected. Observed crack patterns for slab 2 agree with that expected for mechanism one and confirms the prediction. Expected and observed crack patterns for the slabs 2, 4, 5, 7 and 9 are tabulated in Table 3.

\section{Comparison between experiment and finite element predictions}

The experimental failure loads and the NLFE predictions are tabulated in Table 1. Except for the seven-column specimen the predicted failure loads are within $10 \%$ of the actual failure load. The observed crack patterns in the sevencolumn specimen suggest tensile membrane action may be a possible reason for this increased capacity.

\section{Conclusions}

Strength assessment of slabs using yield line analysis and nonlinear finite elements were presented. Agreement between predictions and experimental results is good. However, the nonlinear finite element analysis required expensive software (DIANA), a good calibration model and considerable amount of computing power and time. Considering the accuracy of the predictions yield line theory is better compared with nonlinear finite element analysis to assess structural elements with low steel ratios.

\section{References}

1. Park, R \& Gamble, W. L., "Reinforced Concrete Slabs", John Wiley \& Sons publication, 2000, p.716.

2. "Dalles et planchers dalles; applications de la théorie des lignes de rupture aux calculs de résistance en flexion, Bulletin d' Information 35 , Comité Européen du Béton", 1962. (The application of yield line theory to calculations of flexural strength of slabs and flat slab floors, Information Bulletin 35, European concrete committee, translated by C.V. Amerongen, Cement and Concrete Association, London, p. 180.)

3. Johansen, K. W., "Yield-line theory", Cement and Concrete Association, London, 1962, p.181.

4. Wood, R. H., Jones, L. L., "Yield-line analysis of slabs", Thames and Hudson, London, 1967, p. 405.

5. Johansen, K. W., "Yield-line Formulae for Slabs", Cement and Concrete Association, London, 1972, p.106.

6. Baskaran, K., "Flexural Behaviour of Reinforced Concrete Flat Slabs Supported on NonRectangular Column Grid", PhD thesis, Cambridge University, 2004, p.219.

7. Baskaran, K, and Morley, C.T, “New Approach to Testing Reinforced Concrete Slabs", Magazine of Concrete Research, No 6, pp. 367-374, 2004.

8. Ingerslev A. "The Strength of Rectangular Slabs". The Institution of Structural Engineers' Journal, vol. 1, January, pp. 3-14., 1923.

9. Ockleston, A. J, "Load tests on a Three Storey Reinforced Concrete Building in Johannesburg", The Structural Engineer, October pp. 304-322, 1955.

10. Park, R., "Ultimate Strength of Rectangular Concrete Slabs Under Short-term Uniform Loading with Edges Restrained against Lateral Movement", Proceedings of the institution of civil engineers, Volume 28, June, pp. 125-150, 1964.

11. Baskaran K. and Morley C.T., "Using yield line theory for Interior Panels of Slabs", Proceedings of the Institution of Civil Engineers, Structures \& Buildings 157, December, SB6, pp. 395-404, 2004.

12. Wang, P. T., Shah, S.P., Naaman, A.E., "StressStrain Curves of normal and Lightweight Concrete In Compression", ACI structural Journal, volume 75, November, 1978, pp. 603-611.

13. Rashid, Y.R., "Ultimate strength analysis of prestressed concrete pressure vessels", Nuclear Engineering and Design, No 7, pp. 334-344,1968.

14. Phillips, D. V., Binsheng, Z., “Direct Tension Tests on Notched and Un-notched Plain Concrete Specimens", Magazine of concrete research, March, pp. 25-35, 1993.

15. Cook, R.D. Finite element modelling for stress analysis, John Wiley \& Sons, INC, USA, 1995, p. 320. 


\section{Appendix}

Consider calculating failure load ( $\mathrm{p} \mathrm{kPa}$ ) for slab 2 according to mechanism one including the edge shear forces. The yield line pattern consists of 16 rigid bodies as shown in Figure 3 . If the deflection at $\mathrm{X}$ is $\delta$ then those at $\mathrm{P}, \mathrm{Q}, \mathrm{S}, \mathrm{Y}$, and $\mathrm{Z}$ will be $0.25 \delta, 0.5 \delta, 0.5 \delta, 0.5 \delta$ and 0.75 respectively $\mathrm{AB}=\mathrm{BC}=\mathrm{CD}=\mathrm{DA}=2 \mathrm{a}=1.2 \mathrm{~m}$ and $\mathrm{YZ}=\mathrm{PQ}=$ $\mathrm{b}=0.3 \mathrm{~m}, \mathrm{DA} B=60^{\circ}$

Work done by the uniform load

$=4 p$ (volume swept by rigid bodies 1, 2, 5 and 6 )

$=\frac{\sqrt{3}}{4} p \delta\left(4 a^{2}+6 a b+2 b^{2}\right)$

Lengths of the simply supported edge shear steel plates along column and middle strips are $2 \mathrm{c}=0.9 \mathrm{~m}, 2 \mathrm{~d}=0.3 \mathrm{~m}$ respectively.

Work done by the edge shear forces

$=8 \mathrm{p}(c a \sin 60 \times 0.375 \delta+d b \sin 60 \times 0.625 \delta)$

Therefore total work done by the external forces $=2.065 p \delta$

This is equal to the energy dissipated across the yield lines. If the total hogging moment resistances across rigid bodies 1,2 and 2,6 are $\mathrm{m}_{3}$, and $m_{1}$ respectively and total sagging moment resistances across rigid bodies 2,3 and 6,7 are $m_{4}$ and $\mathrm{m}_{2}$ respectively

Then energy dissipated across yield lines

$=\left(8 m_{1}+4 m_{2}+8 m_{3}+4 m_{4}\right) \times \theta$

where $\theta=2 \delta / \sqrt{ } 3 a$ is the relative rotation between rigid bodies obtained from the hodograph.

From calculations considering the number of bars crossing the yield line, width, effective depth $=40 \mathrm{~mm}$, and strength values for concrete and steel

$m_{1}=1.17 \mathrm{kNm}, m_{2}=0.76 \mathrm{kNm}$

$m_{3}=1.05 \mathrm{kNm}, m_{4}=0.5 \mathrm{kNm}$

Substitution of these values gives the total energy dissipated across yield lines

$=22.8 \times 2 \delta / \sqrt{ } 3 a=43.88 \delta$

From work equation

Work done by the external forces = Energy dissipated across the yield lines suggesting

$21.25 \mathrm{kPa}$ as the failure load. 